\title{
Changes of land use in Fulbaria and Trishal upazila of Mymensingh district of Bangladesh
}

\author{
J. Akther ${ }^{1}$, M. A. Kader ${ }^{1}$, M. Rahman ${ }^{2^{\star}}$ and M. Shawkhatuzzaman ${ }^{2}$ \\ ${ }^{1}$ Department of Soil Science, Bangladesh Agricultural University, Mymensingh-2202, and ${ }^{2}$ Soil Resource \\ Development Institute, Mymensingh-2200, Bangladesh, `E-mail: mail2mukit@gmail.com
}

\begin{abstract}
There is no reliable information till now on the conversion rate of agricultural land in Bangladesh into different non agricultural sectors. The study was undertaken to estimate the present land use pattern and to calculate the changes in land use of agricultural and non-agricultural field over time using aerial photographs of Trishal and Fulbaria upazila of Mymensingh district. Two series of aerial photographs of both upazilas from 1983 and 2000 at scales of 1:40,000 and 1:25,000, respectively, were studied. Land use categories were calculated by random line drawing method on effective areas of aerial photograph. In 1983, Total agricultural and non-agricultural land of Trishal upazila were found 29,505 and 4,095 ha accounting 87.81 and $12.2 \%$ of total land area, respectively. In Fulbaria upazila for the same year, it was 35,611 and 4,258 ha accounting $89.3 \%$ and $10.7 \%$ of total land area, respectively,. An amount of about 3545 and 3637 ha agricultural land was transformed into non-agricultural land in Trishal and Fulbaria upazila, respectively, within a period of 17 years. The rate of decreasing agricultural land to non agricultural land in Trishal and Fulbaria upazila was estimated to be 0.62 and $0.54 \%$ /annum, respectively. Land use analysis shows that conversion of agricultural land into settlement, transport network and water body contributed $88.07,5.3$ and $6.63 \%$ of the land loss, respectively in Trishal upazila and 98.45, 1.3 and $0.12 \%$ of the land loss, respectively in Fulbaria upazila. If similar trends in loss of agricultural land remain constant, there will be no land available for cultivation after around 200 years. Therefore, it is very crying need for the country to make a land use policy for food security of the rapidly growing population.
\end{abstract}

Keywords: Land use, Changes of agricultural land to non-agricultural land

\section{Introduction}

Bangladesh is one of the most densely populated countries in the world having only 12.5 decimals per capita cultivated land (BBS, 2011). With the growing population, and their increasing needs in various sectors, land use patterns are changing over time with the loosing of cultivated land. In a densely populated country like Bangladesh, which is already experiencing high pressure on its natural resource base, a decline in the availability of agricultural land could have devastating consequences on the country's ability to achieve sustainability and maintain self-sufficiency targets, as well as in guaranteeing the food security of households with agriculturally based livelihoods.

Natural land cover is changing by interfere of human in meeting cultivation, homestead, infrastructures or other demands. Reportedly, over the last 30-40 years, the availability of agricultural land has been declining at the rate of $1 \%$ per year (Planning Commission, 2009). If this is true, at least one quarter of the country's agricultural land has been lost over the last 30-40 years. Although the $1 \%$ figure is widely quoted, reliable and scientifically based data quantifying the extent of fertile and arable agricultural land and the changes in availability of agricultural land, is not available. The lack of accurate information on the pattern and magnitude of change in land availability undermines the ability to take action since policy makers are unable to determine where and what actions are needed and where they are most needed (Hasan et al., 2013). In these circumstances, the study was undertaken to estimate the present land use pattern of Trishal and Fulbaria upazila of Mymensingh district using aerial photographs and to calculate the changes in land use in agricultural and non-agricultural field over time.

Aerial photos recorded all visible features on the Earth's surface from an overhead perspective. Land cover/land uses are classified often on the basis of tone, texture, pattern, shade and other features of the aerial photographs. The interpretation of aerial photograph may vary from interpreter to interpreter due to differences of vision and experience. In spite of these limitations, it is realized that the application of aerial photography in the calculation of land uses is most useful technique in Bangladesh where satellite system is not well developed. 


\section{Materials and Methods}

The study was conducted in the district office of Soil Resource Development Institute (SRDI), Mymensingh. The study areas were two upazilas of Mymensinghviz; Fulbaria and Trishal. The experimental site Fulbariaand Trishal are comprised of 39,870 (Islam, 1992) and 33,601 ha of total lands (Alam, 2008), respectively. Two series of aerial photographs of both upazilas from 1983 and 2000 at scales of 1:40,000 and 1:25,000 respectively were collected for this study. Due to unavailability of 2010's photographs most recent data could not be gathered in this study.

\section{Fixing effective areas of the photographs}

The photo survey was designed to acquire 60 percent forward overlap (between photos along the same flight line) and 15-25 percent lateral overlap (between photos on adjacent flight lines). Effective area was the main area of a photograph by deducting the overlapped area. At first the centre of two adjacent aerial photographs, called the principal point, was marked. Secondly, the principal point of the right image was plotted in its position on the left image. At the same time the principal point of the left image was also plotted on the right image. These principal points and transferred points were aligned along a straight line. Then the 20 percent overlapping area of two adjacent runs was deducted. Finally, remaining area as in rectangular shape was considered as effective area of the photograph (Fig. 1).

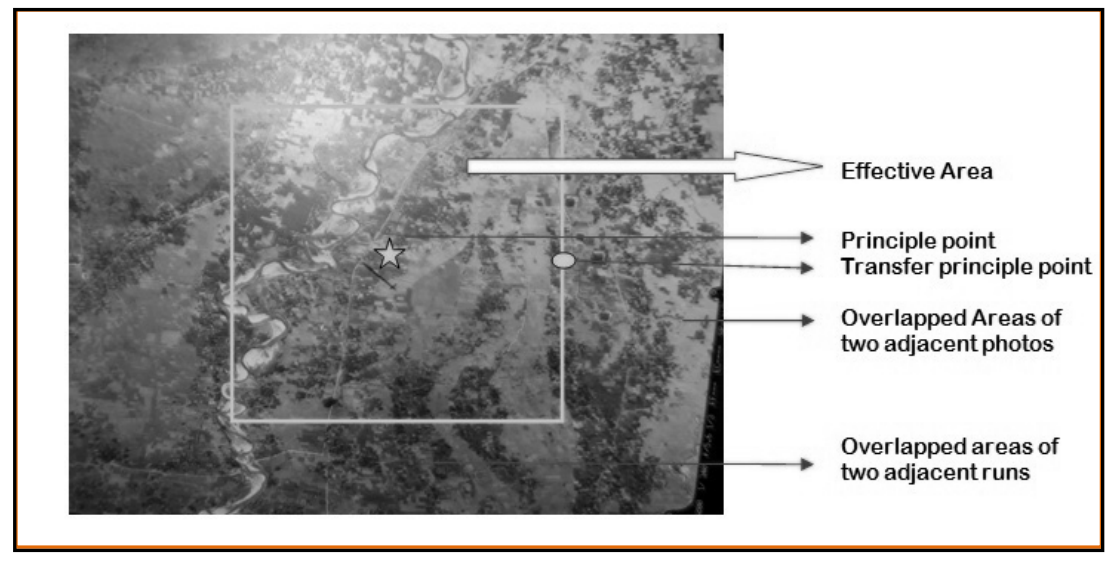

Fig. 1. Fixation of effective areas of an aerial photograph

\section{Analysis of aerial photographs}

This phase deals with delineating different categories of land cover and land use in the study area. This study resorts to human skills in photo interpretation to identify and delineate land use and cover classes. Each of those land use categories was discerned from the others by a combination of tone and texture.

\section{Measurement of land use by category}

Random line drawing method was followed for the measurement of land use in Fulbaria and Trishal upazila. In this method, firstly effective area of a photograph was drawn on aerial photographs by using sharp pencil. Then several parallel lines were drawn on the rectangular effective area on photo maintaining a distance of $1 \mathrm{~cm}$ between the parallel lines. For an example, Fig. 2 shows the parallel lines drawn on the rectangular effective area of an aerial photo maintaining a distance of $1 \mathrm{~cm}$ between the parallel lines. Finally, land uses were calculated for each parallel line drawn on the effective area.

\section{Calculation procedure}

The linear distance of each land use category was calculated from the parallel lines drawn on the rectangular effective area of an aerial fig. The cumulated linear distance of each land use category was summed again to calculate the total linear distance. Then the cumulated linear distance of each land use category was divided by the total linear distance and multiplied by 100 to convert each land use into percentage. For example, if there are 8 lines on an effective area having $10 \mathrm{~cm}$ length, then the total length is $80 \mathrm{~cm}$. In these $80 \mathrm{~cm}$, if water body covers $2 \mathrm{~cm}$ then the percentage of water body is $2 / 80 \times 100=2.5 \%$. 


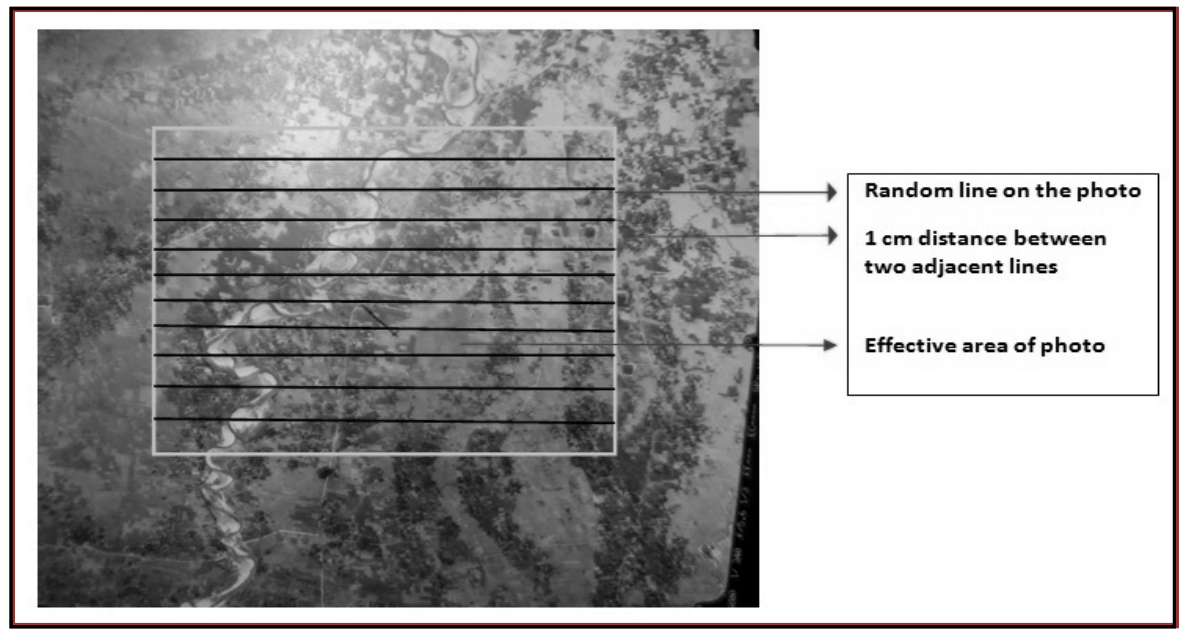

Fig. 2. Measurement of land use by drawing random line on aerial photo

\section{Results and Discussion}

\section{Land Use of Trishal upazilain 1983 and 2000}

Total area of Trishal upazila is about 33,601 ha (BBS 2001). From image interpretation, total agricultural and non-agricultural land (1983) of this upazila was found 29505 ha and 4095 ha accounting $87.81 \%$ and $12.19 \%$ of total land area. Non-agricultural land was comprised of 3682 ha settlement, 67 ha transport network and 346 ha water body accounting $10.96 \%, 0.20 \%$ and $1.03 \%$ of total land area (Fig. 3).
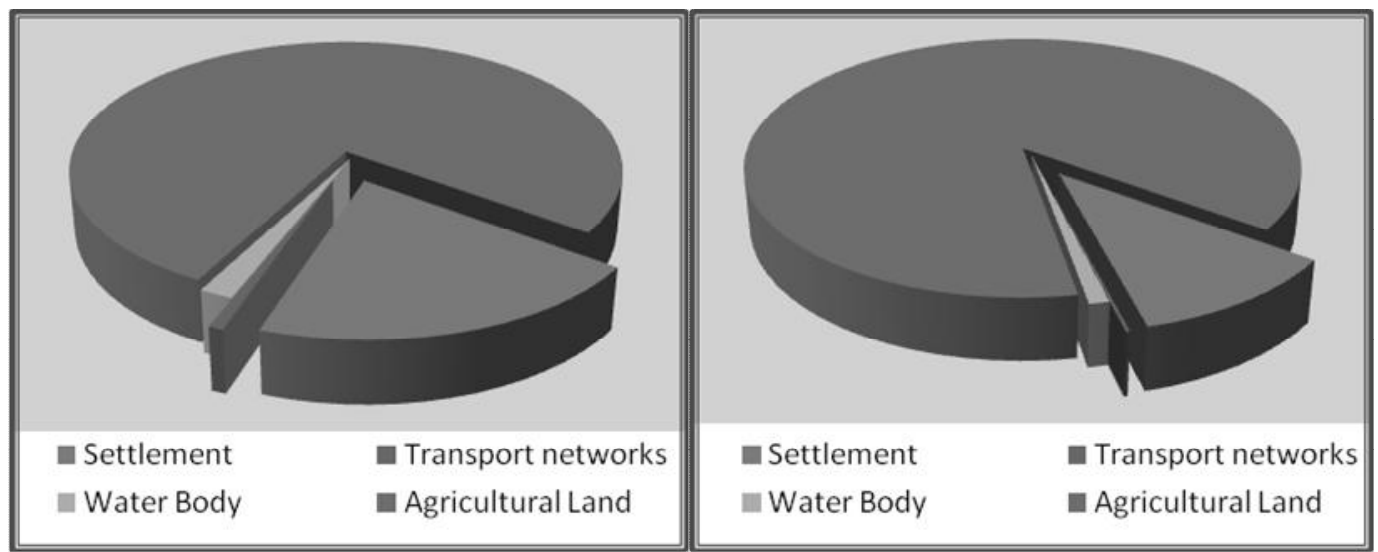

Fig. 3. Categories of land use in Trishal upazila in 1983 (left) and 2000 (right)

In 2000 , total agricultural land of this upazila was estimated to be 25960 ha representing $77.26 \%$ of total land area and total non-agricultural land was estimated to be 7640 ha representing $22.74 \%$ of total land area. Non-agricultural land was comprised of 6804 ha settlement, 255 ha transport network and 581 ha water body representing $20.25 \%, 0.76 \%, 1.73 \%$ of total land area respectively (Fig. 3 ). This result is very close to the Soil Resource Development Institute's (SRDI) result where they reported that at Trishal upazila about 78.3 percent of total land was under agriculture in 1996 (Land Use Map, SRDI, 1996).

\section{Land use changes in Trishal upazila}

The land cover change analysis, based on the comparison between the 1983 and 2000 aerial photos, was accomplished to quantify land transformations and evaluate how land cover changed in the time interval. An amount of about 3544.9 ha agricultural land was transformed into non-agricultural land in Trishal upazila within a period of 17 years from 1983 to 2000 . It accounts $10.55 \%$ of total land area of this upazila (Fig. 4). 


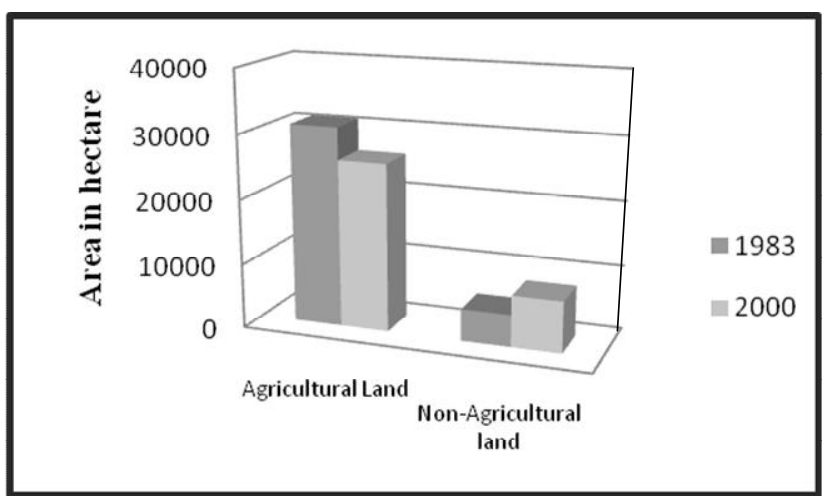

Fig. 4. Agricultural and non-agricultural land in TrishalUpazila between 1983 and 2000

The rate of decreasing agricultural land to non agricultural land in Trisal upazila was $0.621 \%$ /annum or 208.5 ha/annum. Majority of agricultural land in Trishal upazila was converted to settlement. Thus, the land coverage under settlement increased from 3682 ha to 6804 ha between 1983 and 2000. Similar result has been reported by Quasem (2011) who estimated an annual conversion of farm land to nonagricultural land to be $0.56 \%$ from a field survey conducted since 2001 to 2008 covering 24 villages of six divisions of the country. There could be different rate of land use change however, it is clear that the agricultural land has been converting to non-agricultural land over time.

\section{Land use of Fulbaria upazilain 1983 and 2000}

Total land area of Fulbaria upazila is about 39,870 ha (BBS 2001). From image interpretation, total agricultural land (1983) of this upazila was estimated to be 35611 ha accounting $89.32 \%$ of total land area and total non-agricultural land was 4258 ha accounting $10.68 \%$ of total land area. Non-agricultural land was comprised of 3396 ha settlement, 231 ha transport network and 634 ha water body accounting $8.52 \%, 0.58 \%$ and $1.59 \%$ of total land area, respectively (Fig. 5).

Total agricultural land of this upazila was estimated to be 31976 ha representing $80.20 \%$ of total land area and total non-agricultural land was estimated to be 7894 ha representing $19.80 \%$ of total land area in 2000. Non-agricultural land was comprised of 6977 ha settlement, 279 ha transport network and 638 ha water body representing $17.50 \%, 0.70 \%, 1.60 \%$ of total land area, respectively (Fig. 5).
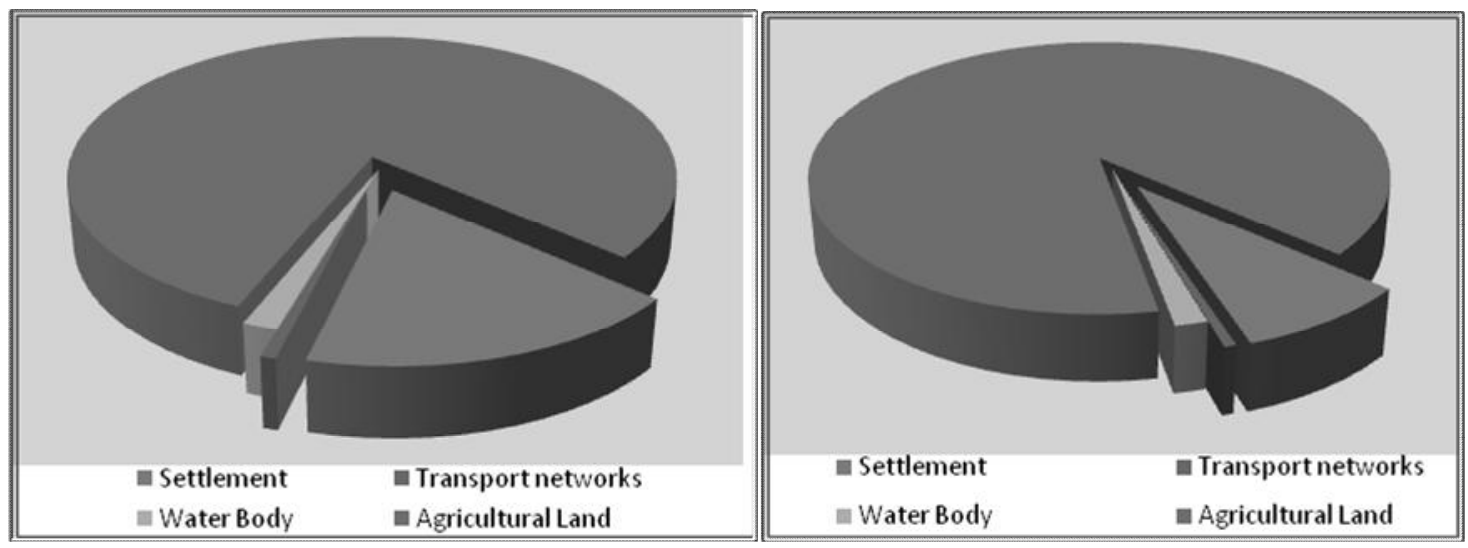

Fig. 5. Categories of land use in FulbariaUpazila in 1983 (left) and 2000 (right)

\section{Land use changes in Fulbaria upazila}

The land cover change analysis, based on the comparison between 1983 and 2000 aerial photos, was accomplished to quantify land transformations and evaluate how land cover changed in the time interval. An amount of about 3636.14 ha agricultural land was transformed into non-agricultural land in Fulbaria upazila within a period of 17 years from 1983 to 2000 . It accounts $9.12 \%$ of total land area of this upazila (Fig. 6). 


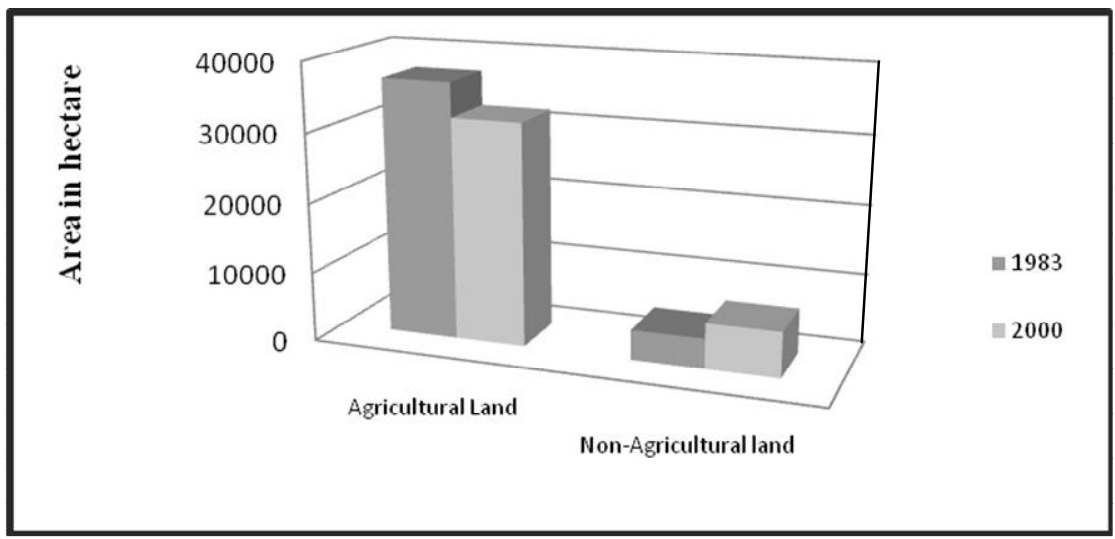

Fig. 6. Agricultural land to non-agricultural land inFulbariaUpazila between 1983 and 2000

Therefore, the rate of decreasing agricultural land to non agricultural land was $0.536 \%$ or 213.9 ha/annum. The land coverage under settlement increased from 3397 ha to 6977 ha between 1983 and 2000. But according to BBS, decline of agricultural land was about $0.383 \%$ annually from $1980-81$ to 2006-07 (27 years average), $0.75 \%$ annually from $1983-84$ to $1993-94$ (10 years average) and $0.40 \%$ annually from 1993-94 to 2003-04 (10 years average) (Quasem, 2011). Differences in land use change among the reported results might be due to use of different protocol in estimating land use change. Majority of agricultural land in Fulbaria upazila was converted to settlement to accommodate the rapidly increasing population. On the other hand, many business enterprises were established in Fulbaria in recent past.

\section{Comparison of land use change in Trishal and Fulbaria upazila}

The rate of change of land use category in both the upazila was bit different but the trend was similar. Rate of decreasing agricultural land to non agricultural land in Fulbaria upazila was $0.536 \%$ or 213.9 ha/annum whereas it was $0.621 \%$ or 208.5 ha/annum in TrishalUpazila. The increment of non-agricultural land was comparatively higher in Trishal than that of Fulbaria.

The rate of change of land use category under non-agricultural land was also different in two upazilas. Percentage of settlement in Fulbaria was increased from 8.52 to 17.5 where it was increased from 10.96 to 20.25 in Trishal upazila (Fig 7). Transport network in Fulbaria was increased from $0.58 \%$ to $0.70 \%$ whereas it was increased from $0.20 \%$ to $0.76 \%$ in Trishal upazila over 17 years (Fig 7). The transport network increased more in Trishal than Fulbaria upazila. Similarly, land coverage under water body was increased much in Trishal upazila compared to Fulabari upazila. In 1983, land coverage under water body represented $1.03 \%$ of total area which broadened into $1.73 \%$ of total area in 2000 . Contrary, land coverage under water body was almost similar between 1983 (1.59\%) and 2000(1.60\%) (Fig. 7).

Majority of agricultural land in both the Trishal and Fulbaria upazila was converted to settlement to accommodate the rapidly growing population. On the other hand, many business enterprises, schoolcollege-madrashas, mosque-girzas were established in recent past with the advancement of economy of the country. Thus, the land coverage under settlement increased from 3682 to 6804 ha in Trishal and 3397 ha to 6977 in Fulbaria upazila between 1983 and 2000. The communication and transport network also developed rapidly with the economic advancement of the country. Thus, the transport network was increased from 67 to 255 ha in Trishal and 231 to 279 ha in Fulbaria upazila between 1983 and 2000. There was a sharp increase in transport network in Trishal compared to Fulbaria upazila. This might be due to the fact that TrishalUpazila has direct connection with capital Dhaka.

In ninty'scommercial fish cultivation became very popular in Mymensingh region as it was profitable compared to crop culture. Therefore, many agricultural lands were converted to water body to construct ponds for fish culture. The large increment in land coverage under water body in Trishal upazila from 346 to 581 ha supports the above assumption. However, it was not found remarkable in Fulbaria upazila. This might be due to the natural availability of some low lying areas in Fulbaria upazila. Thus, the land overage under water body represented $1.54 \%$ of the total area in 1983 which was much higher than the land area 
under water body in Trishal upazila (1.03\%) in the same year. These natural water bodies were shrinking over time naturally due to sedimentation coming from uplands. Moreover, part of these water bodies was filled artificially for settlement. Therefore, we expect a decrease in share of land under water body with time. However, there was slight increase in land under water body in 2000 representing $1.60 \%$ of the total land area. These slight increases in land under water body might be due to conversion of land in water body by constructing ponds for fish cultivation.

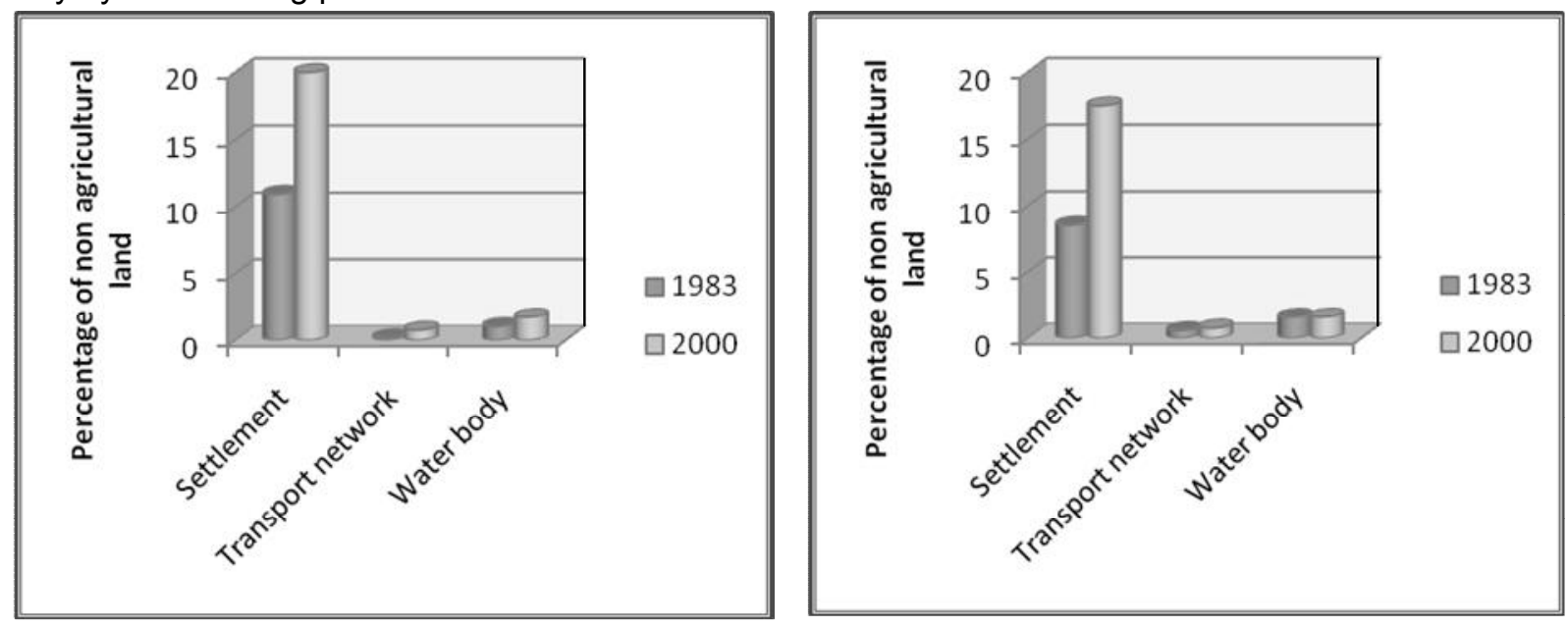

Fig. 7. Comparison of components of non-agricultural lands between 1983 and 2000 in Trishal (left) and Fulbaria (right) upazila

The increment of non-agricultural land was comparatively higher in Trishal than that of Fulbaria may be due to location of the upazila. Trishal is located on the side of Dhaka-Mymensingh highway where establishment rate of various industries and business enterprises were quite higher than the Fulbaria.

\section{Summary and Conclusion}

Rate of decreasing agricultural land to non agricultural land in Fulbaria upazila was $0.54 \%$ or 213.9 ha/annum, whereas $0.62 \%$ or 208.5 ha/annum was in Trishal upazila. From this study, it can be concluded that agricultural land of Trishal and Fulbaria upazilahas been decreasing day by day which is similar to our national scenario. Majority of agricultural land in both upazila was converted to settlement for accommodating the rapidly growing population. On the other hand, many business enterprises were established in Trishal and Fulbaria upazila in recent past. With the economic advancement of the country there was an improvement of communication and transport facilities. Thus, the transport network was also increased. If similar trends in loss of agricultural land remain constant, there will be no land available for cultivation approximately after 200 years. The result of this study will be very helpful for the nation because there is no solid information available till now based on scientific basis. Decreasing rate of agricultural land is alarming for our national economy particularly to feed the rapidly growing population.

\section{References}

Alam, S. 2008.Land and Soil Resources Utilization Guide, Trishal upazila, Mymensingh district, Bangladesh.

Bangladesh Bureau of Statistics. 2001. Population Census 2001: Ministry of Planning, Government of the People's Republic of Bangladesh, Dhaka, Bangladesh.

Bangladesh Bureau of Statistics.2011. Agricultural Census of Bangladesh: Ministry of Planning, Government of the People's Republic of Bangladesh, Dhaka, Bangladesh.

Hasan, M.N., Hossain, M.S., Bari, M.A., Islam, M.R. 2013.Agricultural land availability in Bangladesh. SRDI, Dhaka, Bangladesh, 42pp.

Islam, N. 1992.Land and Soil Resources Utilization Guide, Fulbaria upazila, Mymensingh district, Bangladesh.

Land Use Map. 1996. Soil Resource Development Institute (SRDI). Dhaka, Bangladesh.

Planning Commission. 2009. Steps Towards Change: National Strategy for Accelerated Poverty Reduction II (Revised). FY 200911. Government of the People's Republic of Bangladesh, Dhaka, Bangladesh.

Quasem, M.A. 2011. Conversion of Agricultural Land to Non-agricultural Uses in Bangladesh: Extents and Determinants, Bangladesh Development Studies, Vol. XXXIV, No.1. 